\title{
Vietnamese Women in Hong Kong: A Women's Perspective on Detention ${ }^{1}$
}

\author{
Maryanne Loughry, Margaret McCallin, Gwen Bennett
}

\begin{abstract}
I spend the day doing nothing. Just eating, staying in my bunk, or walking around the camp. I put the future out of my mind.
\end{abstract}

\section{Introduction}

To better understand the situation of the Vietnamese women in detention camps in Hong Kong and the subsequent impact of detention on these women and their children, Community and Family Services International (CFSI), in co-operation with the International Catholic child Bureau (ICCB), conducted a systematic assessment of the needs of the women, and the stresses and traumas experienced by the women as well as their children.

The objectives of this two part assessment were to:

1. enable representative groups of women in the camps to articulate their concerns and needs;

2. share these with women in other camps so as to understand their situation more objectively;

3. document the psychological effects of detention on women and their children; and

4. provide relevant data to program managers to assist them in the development of suitable and relevant programs in Hong Kong and Vietnam.

The assessment provided data on the women's experiences of trauma on the journey to Hong Kong and while in detention, their perceptions of daily problems and needs, and their stress levels including the experiences of trauma and stress levels of their chil-

\footnotetext{
Maryanne Loughry is the team leader, training and resource unit, and Gwen Bennet is the program coordinator, the Community and Family Service International. Margaret McCallin is the director of refugee children program, International Catholic Child Bureau, Geneva.
}

dren under 10 years of age. It examined the cumulative effects of these factors on the women's well-being and their capacity to function while in detention as well as the possible implications for their future. The women in detention actively participated in all stages of the assessment. Thus, in addition to relevant comments within the text, interspersed throughout the report are "vignettes" which describe their lives and give voice to their needs and concerns.

\section{Background}

The Vietnamese people first began seeking asylum in Hong Kong in 1975, and continued to land in the Territory in significant numbers until late 1991. Up until mid-June 1988, all arrivals from Vietnam were recognised as refugees and were eligible for resettlement. In 1988 Hong Kong introduced a refugee status determination procedure. Under this policy, Vietnamese are held in closed detention centres pending a determination of their refugee claim. For many individuals this process has taken at least two years. If denied refugee status, the options are limited to returning to Vietnam under a UNHCR voluntary repatriation program, or the orderly return program agreed by the Hong Kong, British and Vietnamese governments. Many of those denied refugee status have returned to Vietnam but thousands have also opted to stay for more years in the detention camps.

\section{Living Conditions in Detention Camps in Hong Kong}

Most of the detention camps are located far away from the built up areas of Hong Kong and are based in the outer islands, the New Territories and towards the China border. A camp is a series of corrugated iron of fibre huts built on concrete blocks isolated form their surroundings by 5 metre high barbed-wire fences. Between the rows of huts are small and bare passage ways devoid of grass and trees. Inside each hut are three tiered high bunks on metal frames accommodating at least one hundred people. Each dwelling space is one wooden plank assigned to two persons with a make shift curtain separating it from the others. Food is prepared at a central kitchen inside the camp and distributed three times a day.

All in detention are required to live under strict rules and regulations extracted form the ones used for prisoners in Hong Kong. The camps are managed by Correctional Services Department (CSD) officers, or the Hong Kong Housing Authority. Voluntary agencies provide basic services in the camps including primary and secondary education for children, pre-school classes and well baby clinics. Basic social work services are provided in all of the camps by CFSI. Recreational and sport activities are very limited and there are few adult programs. The voluntary agencies working in the camp and visitors to the centres visiting rooms have to comply with the prison rules as distributed by the Correctional Services Department.

The conditions within the camps are cramped and crowded with restrictive movement. They accommodate up to 20,000 people and some of these people have been in detention since 1988, five years. There are countless social problems in the centres including, theft, riot, gambling, alcohol and drug abuse, violent crimes and forced sexual relationships. The most vulnerable people under these circumstances are the women and children, especially those children unaccompanied by their parents. The women com- 
prise approximately 40 percent of the population.

\section{Methodology}

The assessment was conducted in two parts, a series of discussions using the focus group discussion methodology and a questionnaire survey. Following a review of the situation of minors in detention conducted earlier in 1992, ${ }^{2}$ it was decided to take the opportunity whilst interviewing the women to also gather information about the experiences and well-being of young children. In the course of the women's survey, therefore, those who had a child in the age group two to four years or five to nine years were also asked about the events their childhood experienced en route to Hong Kong and in the detention centres, and completed a schedule describing stress related behaviours appropriate to the age of the child. It should be noted that the sample was not controlled to select children in these age groups. There were 67 women with a child in the five to nine age group, and sixty-two with a child aged two to four.

\begin{abstract}
A woman in Whitehead detention centre spoke vividly of the on-going experience of witnessing and being a victim of violence. During the three years they have lived in detention, her family has been robbed several times, and once her husband was beaten when he tried to intervene. They have also witnessed two riots. One in particular, in which twenty four people perished in a fire, has left deep scars. Their children regularly wake up fearful, crying and recalling the screams, the noise of the people running and the terror of that night.
\end{abstract}

\section{Focus Group Discussions}

A series of focused discussions were conducted in five camps, in which 1065 women between the ages of 18 and 70 years participated. Of the total group, there were 320 single women; 232 female heads of families; and 513 married women. While the assessment was co-ordinated by the Training and $\mathrm{Re}$ source Unit of CFSI, the discussions and collection of information were conducted in Vietnamese by Vietnamese women, who were trained in the methodology of focused discussion groups. This was viewed by CFSI as an important factor to empower the women in the camps to "own" the outcomes of the needs assessment.

The process of the Focus Group Discussions (FGD) involved bringing together six to eight women, to discuss the issues and needs that are important to women in detention. The FGD process was thought to be the most suitable process because it gathered women together in a manner that was considered to be culturally sensitive. The process ensured that women had time to express fully their opinions and to experience the support of other women voicing similar concerns. The women who took part in the FGD were from a similar background, education level, age or marital status - for example, single women or married women from one hut. The careful selection of group members was designed to enable the women to identify with each other and hopefully feel more comfortable sharing concerns on encountered issues.

The Focus Group Discussions were conducted at two levels:

\section{Level One}

The objective of level one was to elicit the needs and problems of Vietnamese women in Hong Kong, through consulting a large and representative group of women in an atmosphere that led to open and frank discussions. The targeted participants differed across camps. Some camps based the participation on representative groups: married; single; single mothers; elderly etc. Others selected hut residents ensuring a wide cross-section of women.

All recordings of the FGD were collected by the Training and Resource Unit of CFSI for collection and analysis. Two Vietnamese research assistants were trained in content analysis and they independently considered the recordings of each FGD, with the task of isolating the dominant themes underlying the problems and needs enunciated in the groups. They sorted for dominance and repetition, striving to summarise the content of the discussions in a manner that was faithful to the original intent of the women. The themes were prioritised by frequency and the importance accorded to them in the discussions.

After the content analysis of the transcripts the problems and needs of the women were determined to be grouped under the following eight themes:

- Joblessness

- Public and personal hygiene

- Medical care

- Stress

- Provisions

- Protection and safety

- Leisure and recreation

- Education of children

\section{Level Two}

A further series of discussions were conducted focusing on the eight dominant themes. The same women were invited to participate in these new discussions to ensure that this new level of discussion built on the discussions of level one. The objective of these discussions was to focus on the major concerns (themes) that had arisen out of the earlier discussions and to further review these concerns in the hope of clarifying the causes and effects of these concerns.

In the different camps the women were invited to select from the eight major concerns uncovered from the level one discussions one or two of the concerns that they would consider important enough to include in a further round of discussions. As in the previous discussions, the women in level two vigorously described their situation, outlining in great detail their experience of the problems, the effects that they saw the problems having on individuals, their families and the community of asylum seekers in each camp.

A questionnaire survey collected data from 370 women who were randomly selected from seven camps. The women were interviewed by trained Vietnamese women using the following questionnaire: 
1. Biodata questionnaire: providing background information on the women's situation in Vietnam and their present living conditions in Hong Kong;

2. Traumatic events schedule: recording the traumatic events experienced by women a)en route to Hong Kong and $b$ ) in detention centres.

3. Daily problems questionnaire: recording the daily problems facing the women in detention centres; and

4. Self-report questionnaire: a measure of emotional well-being.

\section{Findings}

The assessment revealed that the cumulative effect of the women's experience of traumatic events and the daily problems that characterize their lives in detention is such as seriously to compromise their emotional wellbeing.

The women are severely depressed and anxious, and their capacity to make decisions, particularly with regard to the future, is thus affected. Women with children are more affected, and the extent to which their children experience negative events is a contributing factor in determining their emotional well-being. They are concerned not only for the effect of the violence that characterizes life in detention on themselves, but also on how it influences their children.

The following summaries reflect the actual content of the women's discussion.

\section{Joblessness}

The women said that employment was their greatest need in the camp. Although in detention centres the daily necessities were provided by the camp management, they considered that employment was the most important because the foods and other items provided in the camp were not considered to be enough for their basic needs. The women believed that working would help to lessen stress and tensions. It would help them feel that their life in detention was more meaningful. They stated that a job would keep them busy and less preoccupied with worries and anxieties and that working could empower them with knowledge and skills which would eventually be helpful for their future.

The women believed that many of the social problems in the camps such as alcoholism and gambling resulted from the people in the camps being left too idle. The combination of joblessness and overcrowded conditions accounted for many of the camps, some of which have resulted in stabbings and murders.

The women concluded that it was essential that there be workopportunities for women in the camps. They saw that such opportunities would not help
The continuing poor hygiene conditions, and the lack of proper maintenance of public areas was evidence to the women that there had not been appropriate measures to encourage or raise people's awareness about public hygiene in detention camps. For them, the attitude of the community towards public hygiene reflected the level of depression present.

\section{Medical Care}

Health care services in the camps was intensely discussed by the women. Most of the concerns were focused on the difficulties that many women experience when they want to seek medical services. The women found that the attitude of health workers, especially

\section{The continuing poor hygiene conditions, and the lack of proper maintenance of public areas was evidence to the women that there had not been appropriate measures to encourage or raise people's awareness about public hygiene in detention camps.}

women to keep occupied but it would also help them to cope with stress and other mental problems in the camp.

\section{Personal and Public Hygiene}

The hygiene conditions in most of the camps was described by the women as very poor. They stated that the washing areas were dirty and there were lots of insects such as flies and cockroaches, and rats, in the living areas. The women stated that these problems were due to the inadequate supply of cleaning equipment, the limited water supply and the lack of care of communal areas resulting in the people not really wanting to care for or maintain their surroundings. As a result of the poor hygiene in the camps there were often outbreaks of diseases such as conjunctivitis, fever and diarrhoea and many of the women weaeere had skin diseases and gynaecological problems. They described these conditions as impacting on their mental health. They saw some of the women in the camps becoming depressed and ill-tempered because of suffering continual illnesses. the doctors in the camps, was usually very negative towards patients. The women reported that they did not feel satisfied with the treatment given. The doctors usually asked too little about their problem and only gave them pain-relief pills. The women reported that the procedures for serious complaints was complicated and lengthy; many described an increased feeling of depression and frustration after seeing the doctor. One of the immediate effects of the women's dissatisfaction was a delay in seeking treatment until the condition became too significant to be ignored.

The discussions concluded that there should be better medical service for Vietnamese women in the camps, and that while recognising that the services available may not be adequate the attitude of the health workers could be improved.

\section{Stress}

Throughout the discussions the women asserted that all women experienced stress and depression in the camps. They felt that the longer they 
were in the camps, the more they were becoming stressed and depressed. They identified three main causes for the women's depression.

Women were living in camps with constant worries and fears. They fear forced repatriation resulting in violence, and they fear that the Hong Kong police could arrest their husband at any time. The women described the camp situation as becoming worse and unsafe for them. The security management in the camps was thought to be bad and the Correctional Services Department could not guarantee the safety of the occupants. They saw that the control in the camp was not strict enough to prevent trouble-makers in the camps, and they saw that in this environment there were more and more people likely to engage in gambling, alcohol and drugs.

For the women the process of screening for refugee status was too slow and unjust. The two year wait for interviews added to the deterioration of the people's mental state because of the long periods of anxiety. They commented that a sign of mental downturn in most women was that they all felt that they were losing more and more of their ability to control their tempers. They witnessed their children dropping out of school due to bad influences in the camps, and they felt the children were easily attracted towards gang activity. They believed that as their children had no contact with the outside world, their minds did not develop normally and they became very difficult to rear. The women also saw their husbands engaging in gambling and drinking due to depression and the women felt powerless to intervene.

Furthermore, the lack of recreational activities left people distressed and in depression.

\section{Provisions}

The women complained that basic necessities provided in camps, specifically food, clothing and underwear, were generally not enough in quantity as compared to their needs, and very poor in quality. The food prepared by the central kitchens lacked taste and some families in the camp had to sell a portion of their food, e.g. fruits, to buy ingredients such as pepper, sugar and fish sauce to recook their food in the manner to which they are accustomed. The women felt that the women in the camps could not enjoy cooking as is the traditional practice and craft of Vietnamese women in Vietnam. In the camps the women could only recook food which was provided cooked but lacking in taste. Many women felt that they had too much time in the camps and if they could not cook they were less help to their family. Most of the women said they were not provided with enough toiletries, footwear, and clothing and they could not get any income-generating work to supplement these needs.

\section{Protection and safety}

In general, women believed they could never feel safe in the camps. They saw that the main cause of the security problems for all, and specifically for women, was the prison-like camp management. They described the "social ills" within this structure becoming increasingly worse. They saw that women as well as children who have always been the victims under these circumstances were living in a state of fear, intimidation, depression and potential conflict.

They felt that nobody actually supported and protected women in the camps.

Under these circumstances they believed that the men did not respect and protect women. In the family, husbands beat up their wives for no reason at all. In the camps' culture the women think that women have become a mockery to men.

Women are teased and forced to submit to sexual relationships. Single women are seen as particularly vulnerable in this condition. The women feel a loss of confidence in themselves. It is because of living in this fear that women never speak up.

They are always fearful for their safety, and for retaliation if they do speak up.

\section{Leisure and recreational activities}

The activities were described as inadequate due to the overcrowded living conditions. There was not enough space for recreational activities and movement within the camp was very restricted. Few materials were available, even magazines. At this point of time, these activities have become more important to lessen the suffering of the people in the camps. They thought that their mental reflexes had slowed down and they were finding it hard to concentrate. Within the camps the women noted that there was no facility available where they could go to forget the hardship that they were facing at the moment.

\section{Education of their children}

The women were concerned about their children's education, the lack of education materials and the skills of the teachers. The majority of the teachers were recruited in the camps, and only a few were former teachers in Vietnam. The majority of the new recruits were only high school graduates, without the skills and experience to be a good educator. As the teachers were also part of the camps, they had their own problems to worry about. Like the rest of the population they were known to experience mental and material problems, they too had lost hope and were living in the camps without purpose. As parents the women were also in the same predicament. They felt that they were not as concerned about their children's education as they would normally be in Vietnam. What preoccupied them was their screening and thoughts about their future, this is given more weight than the importance of their children's education. In this repressed environment the women witnessed that the children were already bearing the harsh living conditions, witnessing all the sufferings and social ills that pervade the camps. They had lost their innocence at a very young age, and had no realistic contact with a normal environment. The women guessed that 
their children had lost their self-confidence, and harbour repressed anger as a result of what they had experienced in the camps. The women believed that their children had stunted learning and development, with no knowledge that what is real in camp is totally the opposite in the outside world.

Overall, the women described themselves as heavily stressed and having to endure a lot of suffering. They described feeling ashamed of themselves and having a very low selfesteem. They were concerned about the chaos in the camps and the message about the Vietnamese community this chaos was giving to the Hong Kong people and the world. In each instance the women related their experience of the problems to the stress and depression that was all too evident to them in the camps. They described their need for meaningful activities as a means through which they could reestablish their own identity and the roles that they were accustomed to filling in Vietnam in preparation for their future. They described feeling helpless to assist their family when it is most in need, and they avoided any discussion of returning to Vietnam where they may at least resume a more active role in providing for the family.

In individual interviews, women will talk about their relationships with their husbands, and how living in detention has changed this. A central factor seems to be lack of privacy and personal space. One woman talked of having no place to share personal thoughts and feelings, or having no place to be alone with her husband intimately. "Your marital relationship is open to all in the hut to see." This makes couples short-tempered, and arguments begin over smaller and smaller things.

In their discussions the women accounted for the lack of concern for public hygiene, the inadequate protection of the vulnerable in the camp and the apathy towards the children's education as symptomatic of the people in the camp living in enormously stressful circumstances. They could see that the circumstances could be improved for them in Hong Kong, and they had many suggestions as to what changes should be brought about.

The women, despite their all-pervasive environment of stress and depression, became focused and energised by their experience of sharing and being listened to. Buoyed by the discussions, and recognising the need for a more thorough assessment the women assisted and participated in a questionnaire survey of a cross section of women from the camps to obtain additional data on the costs of detention on women.

A mother of three living in Whitehead detention centre says her constant anxiety is "to keep her family in peace and happiness." She says living in the huts is like living in the middle of a market, where your children see and hear everything, and others watch all the time. She feels she has little control over her children's emotional development and well-being.

\section{Conclusions and Recommendations:}

Although the assessment was conducted with women and focused on issues that are of particular importance to them, it would be counter-productive for the results to be shared only with them. In many respects, the negative effect on their emotional well-be-

\section{In many respects, the nega- tive effect on their emotional well-being is due to their situation of disempowerment and vulnerability as women.}

ing is due to their situation of disempowerment and vulnerability as women. They are not the perpetrators, but the victims of abuse, intimidation and neglect of their needs and concerns as women and as mothers. In this sense it is important that the community understands the severe effects on both women and children if the situation continues unchanged. "Community" is meant to convey not only the Vietnamese in detention, but the voluntary, international and governmen- tal agencies that work in the detention camps. These organizations must not leave the population in detention to face the reality of their circumstances unaided, nor use the results from the assessment as another stick with which to beat them. The bleak picture which emerges from the assessment demands that the population in detention be enabled by humanitarian means to resolve the impasse that is so evident in their inability to reach a decision about their future, whilst recognising the effects of detention on themselves and their families. This latter issue was discussed in the meetings with the women, albeit often in an "oblique" manner, and bearing in mind that in the majority of cases it is not the woman herself who makes decisions, but her husband/partner or other male family member.

1. The results of the assessment should be shared with groups of people in detention, through a process of community education, and also with the agencies working in the detention camps, UNHCR, and camp management. This information campaign needs to be carefully planned to ensure full dissemination throughout the camps as well as at different levels within the involved organisations. A high profile interagency campaign to launch the Women's Report and to disseminate the results could serve as a catalyst to further enhance the women's network as well as develop their involvement and resourcefulness. Such an interagency approach could also facilitate the design of programs to respond to the needs substantiated by the assessment.

2. The assessment results should also be shared beyond Hong Kong in an attempt to address the needs of women and their children when they return to Vietnam. It may be possible to target government bodies, women's groups and organisations already operating in Vietnam, and particular organisations assisting with the reintegration of returning Vietnamese. 